\title{
ATTRACTING ANTAGONISTS: DOES FLORAL NECTAR INCREASE LEAF HERBIVORY?
}

\author{
LynN S. AdLeR ${ }^{1,3}$ AND Judith L. Bronstein ${ }^{2}$ \\ ${ }^{1}$ Department of Biology, 2119 Derring Hall, Virginia Polytechnic Institute and State University, Blacksburg, \\ Virginia 24061 USA \\ ${ }^{2}$ Department of Ecology and Evolutionary Biology, University of Arizona, Tucson, Arizona 85721 USA
}

\begin{abstract}
Traits that are attractive to mutualists may also attract antagonists, resulting in conflicting selection pressures. Here we develop the idea that increased floral nectar production can, in some cases, increase herbivory. In these situations, selection for increased nectar production to attract pollinators may be constrained by a linked cost of herbivore attraction. In support of this hypothesis, we report that experimentally supplementing nectar rewards in Datura stramonium led to increased oviposition by Manduca sexta, a sphingid moth that pollinates flowers, but whose larvae feed on leaf tissue. We speculate that nectar composition may provide information about plant nutritional status or defense that floral visitors could use to make oviposition decisions. Thus, selection by floral visitors and leaf herbivores may be inextricably intertwined, and herbivores may represent a relatively unexplored agent of selection on nectar traits.
\end{abstract}

Key words: $\quad$ Datura stramonium; herbivory; Manduca sexta; mutualism; natural selection; nectar composition; nectar reward; oviposition; pollination.

\section{INTRODUCTION}

Many well-known traits have evolved in the context of attracting and rewarding mutualists. Nectar, a sugarrich substance produced by many plants that manipulates their biotic pollinators into transporting pollen, is undoubtedly one of the best-studied rewards from both the ecological and the evolutionary perspective. However, attractive traits often attract nonmutualistic organisms, as well as mutualists, that under some conditions inflict severe costs (Bronstein 2001a, $b$ ). For example, many animals that feed on nectar do not effect pollination (Irwin et al. 2001), and some nectar-consuming pollinators inflict damage that can outweigh the benefits of their actions (e.g., Pettersson 1994, Thompson and Cunningham 2002). To understand how rewards and, hence, mutualisms evolve, one should consider the selective pressures that result from these combined interactions.

In this paper, we present evidence that nectar not only may attract antagonists such as nectar robbers, but also may increase herbivory. We describe systems in which pollination and herbivory may be linked, develop the hypothesis that attraction of pollinators increases attraction of herbivores, describe systems likely to exhibit this trade-off, present data from a preliminary test of this hypothesis, and speculate briefly on the role of nectar composition in providing information about plant quality to ovipositing insects. Finally, we draw

Manuscript received 12 June 2003; revised by 24 July 2003; accepted 25 July 2003. Corresponding Editor: A. A. Agrawal. For reprints of this Special Feature, see footnote 1, p. 1477.

${ }^{3}$ E-mail: 1sadler@vt.edu parallels with other pollination systems and other mutualistic interactions.

\section{Links Between Attraction of Pollinators AND Antagonists}

Although plant-herbivore and plant-pollinator interactions have been extensively studied, only recently has it been recognized that the two phenomena are far from independent (e.g., Armbruster 1997, Brody 1997, Strauss 1997, Strauss et al. 1999, Adler 2000a, Herrera 2000, Herrera et al. 2002). Many plant traits that putatively evolved in the context of herbivore resistance have been shown to influence pollinator preference and/ or visitation. Chemical defenses against herbivores can deter pollinators, either directly by their presence in floral tissue or nectar, or by their requirement for resources that otherwise could have been allocated to pollinator attraction (Strauss et al. 1999). The effects of plant defense against herbivores on pollinators are not strictly negative, because the consequent reduction of herbivory can indirectly make plants more attractive to pollinators (Adler et al. 2001).

Conversely, floral traits that have presumably evolved to attract pollinators (e.g., Chittka and Thomson 2001) have the potential to attract antagonists as well. Common examples of such antagonists include nectar robbers and thieves that damage floral structures (Maloof and Inouye 2000, Galen and Cuba 2001, Irwin et al. 2001), floral herbivores (Nitao and Zangerl 1987, Zangerl and Rutledge 1996, Wolfe 1997), predispersal seed predators (Augspurger 1981, Campbell et al. 1991, Brody 1997), and fungal pathogens (Elmqvist et al. 1993, Shykoff and Bucheli 1995, Shykoff et al. 1997). Many of these antagonists are attracted to flowers pos-

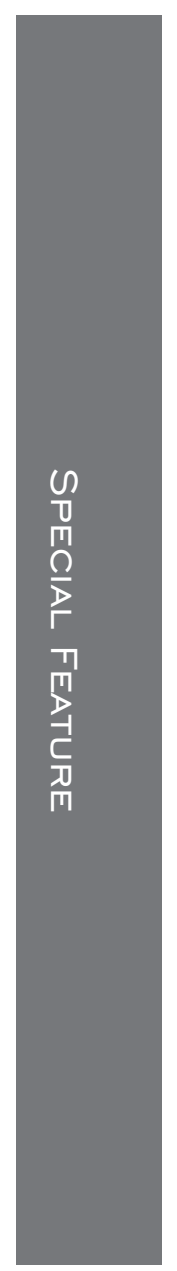


sessing the same set of traits that attract legitimate pollinators, which may make it difficult for plants to escape antagonists without simultaneously deterring pollinators. For example, both bumble bee pollinators and destructive nectar-foraging ants prefer funnelshaped to tubular flowers in Polemonium viscosum. Galen and Cuba (2001) found that flowers with experimentally constrained tubular shapes were avoided by ants, but also received less pollen and set fewer seeds than controls, demonstrating that defense against ants comes at the cost of pollinator deterrence. Similarly, experimentally manipulated plants of Ipomopsis aggregata with large flower displays received more flower visits by pollinators, but also more pre-dispersal seed predation (Brody and Mitchell 1997).

Shared biosynthetic pathways or linked genes can affect interactions with both pollinators and herbivores. For example, in Ipomoea purpurea, the compounds responsible for flower color and for chemical defenses against herbivores are produced by a shared biosynthetic pathway, so that floral morph is related to leaf herbivore survival (Simms and Bucher 1996, Fineblum and Rausher 1997). Preferences of a diversity of herbivores (Irwin et al. 2003) and pollinators (Stanton et al. 1989) also vary with color morphs of Raphanus raphanistrum. Chemical defenses in petals are higher than in leaves and vary between color morphs, suggesting that the mechanism for differential herbivore resistance between morphs is linked to these defenses (Strauss et al. 2004). Corollas of Nicotiana attenuata produce nicotine volatiles, but levels decrease at times when pollinators are most active (Euler and Baldwin 1996). Thus, traits that influence pollinator attraction and those that influence herbivore defense may often be tightly linked.

Nectar itself plays a role in attracting nonpollinating antagonists. For example, plants growing adjacent to floral nectar sources of different plant species may receive more oviposition and damage by lepidopteran herbivores (Murphy et al. 1984, Karban 1997). In agricultural cotton, diverse lepidopteran and hemipteran herbivores prefer to oviposit on cotton varieties with extrafloral nectaries compared to nectariless varieties (Lukefahr and Rhyne 1960, Schuster et al. 1976, Flint et al. 1988). Reducing extrafloral nectar in wild cotton also reduces herbivory by leaf miners when ant predators are absent (Rudgers and Gardener 2004, this Special Feature). Thus, production of nectar nearby or on the same plant can increase herbivory by a diversity of species.

\section{Trade-offs Between Attraction of Pollinators and Herbivores: Potential Systems}

The previous examples have demonstrated that plants may suffer increased herbivory via extrafloral nectar production or via proximity to a source of floral nectar. We hypothesize that herbivory is also higher on individual plants that produce more floral nectar than on conspecifics with lower floral nectar production. We make this prediction for systems in which insect pollinators also deposit their herbivorous offspring on the same plant. If adults prefer plants that produce high nectar volumes (e.g., Real and Rathcke 1991, Hodges 1995), then nectar production patterns seem likely to be under simultaneous selection in the context of attracting pollinators while minimizing the linked cost of herbivory.

We are most aware of the potential for a trade-off between herbivory and pollination by the same species in Lepidoptera. Members of the family Sphingidae (the hawkmoths) provide perhaps the best examples of herbivorous larvae that specialize on the same plants pollinated by adults. Such herbivory may represent a significant cost to plants; for example, an individual Manduca sexta larva can defoliate its host by the time it pupates (McFadden 1968). Examples of sphingids that pollinate as adults and feed as larvae on the same plant species include Manduca sexta and M. quinquemaculata on several solanaceous species (Madden and Chamberlin 1945); M. florestan on Tecoma stans (Hodges 1971; K. Kester, personal communication), and Hyles lineata on Oenethera caespitosa (R. Raguso, unpublished data). Among other Lepidoptera, Pieris rapae (Pieridae) is an efficient pollinator of Raphanus raphanistrum (Conner et al. 1995), and larval P. rapae are specialists on crucifers including this species (e.g., Agrawal 1999). Finally, several moths and butterflies that are generalist nectar feeders as adults and generalist herbivores as larvae may incorporate certain plant species in their diets at both life history stages; examples include Heliothis virescens and Helicoverpa armigera (Cunningham et al. 1998, De Moraes et al. 2001). This is not intended as an exhaustive list, but rather as examples that demonstrate the potential for such trade-offs.

The other main orders that include large numbers of species in which adults are nectarivorous and larvae are herbivorous (broadly defined) are the Diptera, Hymenoptera, and possibly Hemiptera. Many syrphid flies feed on nectar as adults (Proctor et al. 1996), and some consume plant tissue as larvae (e.g., Grosskopf et al. 2002). Other Diptera and some Hymenoptera have nectar-feeding adults and leaf- or stem-galling larvae, and Megachilid bees cut leaves for use as nesting material. We are not aware of other bees that could act as potential herbivores, unless one considers feeding on pollen to be a form of herbivory. Data on cotton suggest that some hemipterans feed upon extrafloral nectar (Schuster et al. 1976, Scott et al. 1988), but we are aware of no studies linking hemipteran herbivory with floral nectar use. In most cases, it is not known whether these nectarivores are effective pollinators; if not, then both the adult and larval stages are potentially antagonistic to the plant. For species that do not pollinate, a link between nectarivory by adults and herbivory by 
Plate 1. An adult Manduca sexta feeding at a Datura stramonium flower. Larval M. sexta are specialist herbivores on D. stramonium and related plants in the Solanaceae. Photo creidt: Lara Call Gastinger.

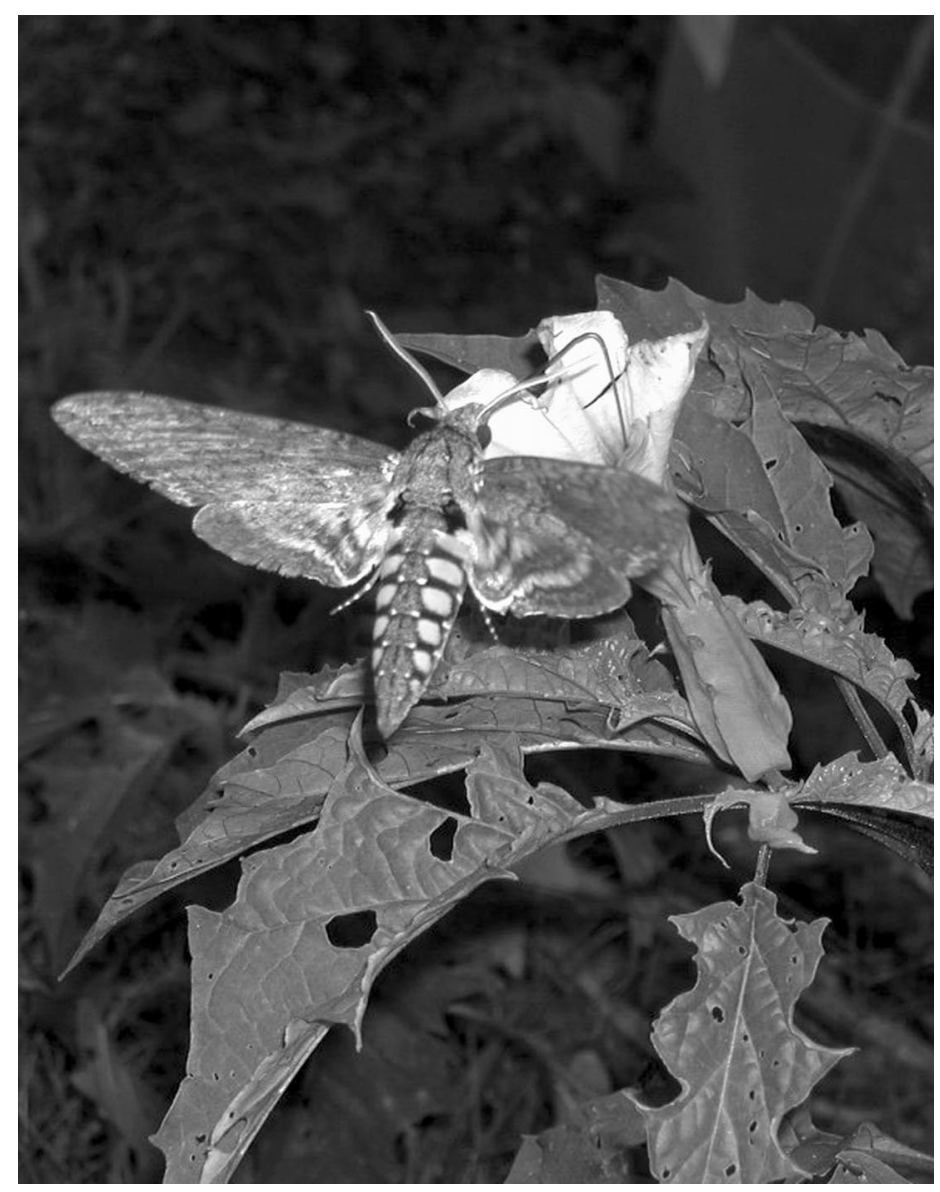

larvae does not create an explicit trade-off for plants in terms of both attracting and deterring the same species, but may still result in conflicting selection on nectar production from these species and the legitimate pollinators.

\section{Does Nectar Increase Herbivory? A Preliminary Test}

We hypothesize that in systems in which an insect species uses the same plant species for both nectaring and oviposition, individual plants that produce more nectar will receive higher egg loads and subsequently will suffer greater rates of herbivory. Here we present new experimental data testing this hypothesis. The annual Datura stramonium (Solanaceae) is an abundant roadside and agricultural weed along the east coast of the United States (Motten and Antonovics 1992). The large white flowers open at dusk, wilt the following day, and are visited by honeybees and the hawkmoths Manduca sexta and M. quinquemaculata (Motten and Antonovics 1992; L. S. Adler, personal observation). Plants are highly self-compatible and set seed in the absence of pollinators (Motten and Antonovics 1992; L. S. Adler, personal observation), although they set more seed from outcrossing (Nuñez-Farfan et al. 1996).
Datura stramonium produces both alkaloids (NuñezFarfán and Dirzo 1994, Shonle and Bergelson 2000) and trichomes (Valverde et al. 2001) as defenses against a diversity of herbivores, and chemical defenses are under natural selection by these herbivores (NuñezFarfán and Dirzo 1994, Shonle and Bergelson 2000). Manduca adults require large volumes of nectar to fuel their flight (Raguso et al. 2003), and oviposit on $D$. stramonium hosts in the field (L. S. Adler, personal observation). M. sexta females require a nectaring visit before they will oviposit (Madden and Chamberlin 1945), suggesting that individuals might remain longer or return repeatedly to plants that offer more nectar, or else that more individuals might visit. The crop volume of an individual M. sexta is $\sim 650 \mu \mathrm{L}$ (R. Raguso, personal communication), far more than the nectar yield of a single Datura flower. However, we often observe several M. sexta probe the same flower during an evening (L. S. Adler, personal observation), suggesting that nectar is not exhausted at the first visit.

To test the hypothesis that increased nectar rewards would increase oviposition by $M$. sexta females, we experimentally manipulated nectar rewards at the plant level, offered an array of plants varying in nectar abundance to caged adult $M$. sexta, and examined subse- 
quent patterns of oviposition. We grew 100 D. stramonium individuals in $3.78-\mathrm{L}$ pots with one application of Osmocote 15-9-12 slow-release fertilizer (ScottsSierra, Marysville, Ohio, USA) soil in the greenhouse with a 16:8 light: dark regime created with alternating $1000-\mathrm{W}$ sodium and metal halide lights. We grew 100 additional plants to serve as sources of nectar. We randomly assigned plants to one of three treatments for the duration of the experiment: nectar supplementation, nectar removal, or control. Plants were treated and used in the experiment whenever they had an open flower. We removed flowers when necessary to insure that each plant had only one flower open per night. We collected supplemental nectar every night from non-experimental plants, pooled the nectar, and then divided it among the flowers in the supplemental treatment. We added an average of $31.3 \pm 2.6 \mu \mathrm{L}$ nectar per flower, compared to a standing crop that averaged $9.4 \pm 0.65 \mu \mathrm{L}$ and ranged from 4.03 to $33.3 \mu \mathrm{L}$. Thus, our supplementation represents a substantial increase in reward, but is not outside the range of natural production. For plants in the removal treatment, we removed nectar from open flowers by inserting a $50-\mu \mathrm{L}$ microcapillary down the corolla of each flower. For control plants, we removed and then replaced nectar to control for handling effects.

We constructed a $4.25 \mathrm{~m}$ long $\times 1.25 \mathrm{~m}$ wide $\times 1.5$ $\mathrm{m}$ high cage of coarse shade cloth suspended over three lights. Manduca sexta pupae (obtained from the Department of Entomology, University of Kentucky colony) of approximately even sex ratios were placed within the cage. Adults mated upon emergence, and females oviposited on $D$. stramonium placed within the cage. Between 6 and 12 adult $M$. sexta were in the cage each night for the duration of the experiment. We applied treatments to flowering plants every evening and then placed them in the moth cage overnight, repeating this procedure from 28 November to 11 December 2001. Generally, every plant that flowered on a given night was treated and used (8-14 plants/night). Hence, there was not always an even ratio of plants in the three treatments every night (the most uneven ratio between treatments was 2-3-4 rather than 3-3-3). When more plants flowered than we could use, we selected plants to create an even ratio and removed flowers from unused plants. Every day we removed the previous night's experimental plants from the cage and counted and removed all eggs. Data were averaged within plants so that individual plants were the unit of replication. In total, 85 plants (25 supplement, 29 control, and 31 removal) were used for analysis; individual plants were treated 1-4 times over the course of the experiment (mean 1.6 times). Although we did not observe pollinator behavior, we allowed flowers to set fruit to determine whether nectar treatment affected fruit set, seed set, and seed mass.

We analyzed oviposition data using ANCOVA, with nectar treatment as the main effect and position in the

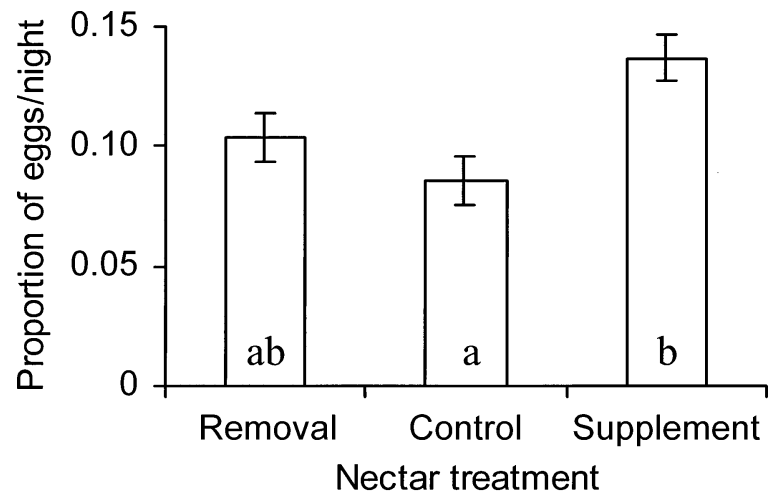

FIG. 1. Effect of nectar manipulation on the proportion of Manduca sexta eggs oviposited on each Datura stramonium plant per night. Error bars represent \pm 1 SE, and different letters represent significantly different means at $\alpha=0.05$ using Duncan's Multiple Range test.

cage, which was randomized across replicates, as a covariate. Position was treated as a continuous covariate because plants were arranged along a line down the length of the cage. Because total oviposition varied greatly among nights, we analyzed the relative number of eggs (i.e., the proportion of total oviposition for that night) deposited each night on each plant. Data were not transformed because they did not differ significantly from a normal distribution. We used Duncan's Multiple Range test (Littell et al. 2002) as a post hoc comparison of oviposition between nectar treatments. We also asked how nectar treatment affected the proportion of flowers that set fruit, seeds per fruit, and seed mass using one-way ANOVAs.

We found that nectar treatment significantly affected the relative number of eggs oviposited per plant $\left(F_{2,81}\right.$ $=3.28, P=0.043)$ after accounting for variation due to position in the cage $\left(F_{1,81}=74.21, P<0.0001\right)$. Duncan's Multiple Range test indicated that plants with supplemental nectar received a greater proportion of eggs than did control plants (Fig. 1), but that oviposition was intermediate on nectar removal plants. We do not know the mechanism underlying this result; if damage from removing nectar attracted moths, we would have expected to see a similar result with the control plants. It is possible that nectar removal without replacement stimulated nectar production, as is found in some other species (e.g., Gill and Conway 1979, Castellanos et al. 2002). In any event, high nectar production increased oviposition relative to controls, but reduced nectar production did not produce a concomitant reduction in oviposition.

Plants with supplemental nectar also set significantly more fruits than did plants in control or removal treatments $\left(F_{2,82}=9.22, P=0.0002\right.$; supplement, $1.5 \pm$ 0.16 ; control, $0.79 \pm 0.16$; removal, $0.65 \pm 0.13$ ), although there was no significant effect on the number of seeds per fruit or on seed mass $\left(F_{2,52}<1.84, P>\right.$ 0.18 for both). There was a nonsignificant trend for 
supplemental-nectar plants to produce the most but lightest seeds, followed by control plants, followed by removal plants producing the fewest and heaviest seeds. Although not significant, this pattern is consistent with nectar-removal plants having received few or no pollinator visits compared to control or supplemental-nectar plants. Flowers of the congener D. wrightii that are not pollinated set significantly fewer but heavier seeds compared to flowers visited by pollinators (Elle and Hare 2002; J. L. Bronstein, unpublished data).

Thus, nectar augmentation increased fruit set (in the absence of herbivores, because eggs were removed), but also resulted in increased deposition of herbivore eggs. Although further observations are necessary, this link is probably a result of longer or more frequent visits of individual $M$. sexta females to augmented plants for nectaring and subsequent oviposition, and a link between the number/duration of nectaring visits and the probability of fruit set in this self-compatible species. These results point to a potentially high cost of associating with a pollinator that is an herbivore at another life history stage.

What is the evolutionary significance of the link between pollinator visitation and the deposition of herbivorous offspring in the D. stramonium-M. sexta interaction? Datura produces copious volumes of nectar (Raguso et al. 2003). It seems likely that nectar production patterns are under simultaneous selection to increase pollen deposition while reducing associated oviposition. However, to show a trade-off between selection by pollinators and herbivores, it is necessary to demonstrate at least the following. First, fruit and seed set should increase with the number of pollinator visits. Because D. stramonium is highly self-compatible, relatively high fruit and seed set may be achieved in the entire absence of pollinating or ovipositing visitors. How much does plant reproductive success increase with successive pollinator visits? Plants with different breeding systems and levels of self-compatibility are likely to experience different balances of cost and benefit from pollinators that are simultaneously herbivores. In systems in which plants are self-incompatible, pollinator preference may play a more important role than in the Datura-Manduca system, shifting the balance of selection toward pollinator attraction in spite of potential costs from herbivory (but see Willmott and Burquez [1996], in which seed set was highest at intermediate numbers of hawkmoth visits). Second, greater oviposition should translate to greater herbivory. The vast majority of $M$. sexta eggs do not survive to become late-instar larvae, due to high predation or parasitism rates (Kester et al. 2002, Mira and Bernays 2002). However, plants receiving more eggs should still be at the greatest risk of damage unless density-dependent processes are involved. Third, increased herbivory should translate to reduced plant fitness. Even if nectar production is under selection by herbivores, ultimately the net direction of selection will depend on the relative costs of herbivory and other antagonists compared to the benefits of pollination and other mutualists in that system. It will be critical to measure selection in the appropriate community context, specifically, in the presence of co-pollinators that are not herbivores, and of co-herbivores that are not pollinators. Finally, it will be necessary to determine if the relationship between nectar volumes and oviposition that we have shown in the laboratory occurs in nature as well, i.e., between wild moths and plants occurring at natural densities.

We hope to see similar studies investigating the role of nectar in attracting herbivores in other systems. It is likely that nectar traits have received relatively little attention in the past due to their notorious variation with environmental conditions such as water and nutrient availability (Real and Rathcke 1991, Wyatt et al. 1992, Boose 1997). Although some studies have found heritable variation in nectar production (reviewed by Mitchell (2004), this Special Feature), it is possible that in many instances selection on nectar production will not result in evolutionary change, due to high environmental variability. However, nectar composition may be less variable than concentration (Gardener and Gillman 2001b). Thus, selection on nectar composition and sometimes on production is likely to influence the evolution of nectar rewards.

\section{Nectar Composition as an Information Cue}

The link between herbivory and pollination can also be considered from the perspective of the insect. Nectar composition may provide important information to adult females that must make rapid oviposition decisions. The link between nectar traits and plant quality is most likely to occur when stress, resources, defense production, or other factors influence composition of many plant tissues, including nectar. For example, adding fertilizer can influence the composition and total concentration of amino acids in nectar (Gardener and Gillman 2001a). If nectar-feeding adults can detect differences in amino acids (Gardener and Gillman 2002), such variation could be used as an indicator of plant nutritional status and subsequent offspring performance. Additionally, nectar in many plants contains defensive compounds (Adler 2000b). If the concentration of defensive compounds in nectar is correlated with that in other plant tissues (L. S. Adler and M. Wink, unpublished data), then nectar composition might provide information to nectar-feeding adults about the level of chemical defense that their offspring would encounter on that plant. Thus, nectar composition as well as volume may be under selection by ovipositing herbivores.

This idea is highly speculative, and rests on several assumptions that can and should be tested: (1) that nectar-feeding adults can discern or "taste" differences in nectar composition (Gardener and Gillman 2002), (2) that differences in nectar composition exist in na-

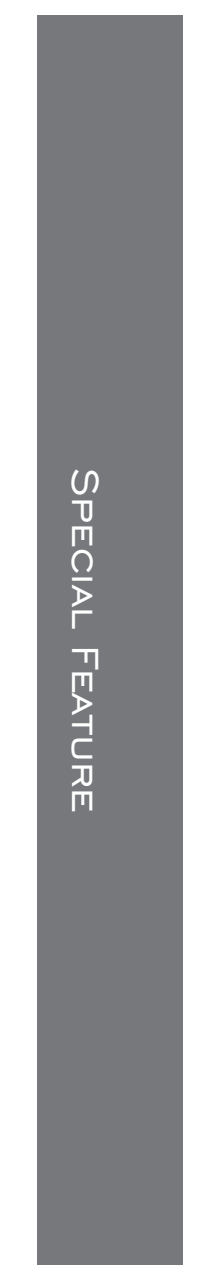


ture and are a reliable indicator of other plant qualities, and (3) that such differences in plant qualities affect offspring performance.

\section{Parallels with Other Systems}

Conflicts between pollination and consumption activities of individual floral visitors exist in two other well-studied pollination systems. The first of these involves pollinators with offspring that consume seeds; the best studied are the mutualisms between figs and fig wasps and between yuccas and yucca moths (e.g., Cook and Rasplus 2003, Dufaÿ and Anstett 2003, Pellmyr 2003). The potential cost of attracting more pollinators is quite evident in these interactions (Bronstein 2001a), although there are some important differences with the linked pollination-herbivory systems discussed in this paper. In particular, pollinating seedparasite mutualisms show much higher species specificity, and the costs associated with pollination are both more severe (because seeds rather than leaves are lost to pollinator offspring) and possibly less easily escaped. A parallel can also be drawn to systems in which pollinators consume pollen, often as both larvae and adults. Notable examples include many ecologically important bee and beetle pollinators (Simpson and Neff 1983). Pollinators that consume some of the pollen they pick up can be inferior mutualists compared to species that feed on nectar (e.g., Ramsey 1988, Wilson and Thomson 1991). Certain floral traits are postulated to have evolved to limit the likelihood of pollen consumption while not deterring pollination itself; for example, some plants present infertile pollen and other protein bodies that serve as alternative food rewards for pollen consumers (Vogel 1978, Simpson and Neff 1983). In both pollinating seed-parasite and pollinating pollen-consumer mutualisms, consumption takes place within the flower, rather than on vegetative structures, as in the interactions described in this paper. However, the ecological parallels are evident; it would not be surprising to find parallels in their evolutionary dynamics as well.

We can readily identify other mutualisms in which a mutualist species also consumes its partner. For example, certain well-studied seed dispersal mutualisms, some of them highly coevolved, involve animals that cache seeds for later consumption but do not recover every seed they cache (Vander Wall 2001). Similarly, ant-defended homopterans must cope with the fact that in certain ecological conditions, their protectors will consume them rather than consuming the honeydew reward that they produce (Offenberg 2001). Under certain circumstances, herbivores can have a net beneficial effect on their host plants by stimulating increased growth and allocation to reproductive structures (Agrawal 2000). Other examples of predatory mutualists can be identified as well (e.g., Janzen 1984, Branch et al. 1992, Bultman et al. 2000). As in the pollination mutualisms discussed in this paper, conflicting selection pressures between the mutualistic and antagonistic components of the same interaction seem highly likely, and are well worth further exploration (de Mazancourt et al. 2001, Gomulkiewicz et al. 2003).

\section{ACKNOWLEDGMENTS}

We thank K. Kester for supplying hawkmoths; D. Wiley for superb greenhouse maintenance; J. Anderson, J. Echague, L. Hill, C. Palmer, and M. Wiggins for assistance with data collection; and A. Agrawal, E. Elle, R. Irwin, K. LeVering, G. Stevens, J. N. Holland, S. Richardson, the members of the Adler lab, and one anonymous reviewer for comments on the manuscript. This research was funded by the Virginia Tech Department of Biology and grant NSF DEB-0211480 to L. S. Adler.

\section{Literature Cited}

Adler, L. S. 2000a. Alkaloid uptake increases fitness in a hemiparasitic plant via reduced herbivory and increased pollination. American Naturalist 156:92-99.

Adler, L. S. 2000b. The ecological significance of toxic nectar. Oikos 91:409-420.

Adler, L. S., R. Karban, and S. Y. Strauss. 2001. Direct and indirect effects of alkaloids on plant fitness via herbivory and pollination. Ecology 82:2032-2044.

Agrawal, A. A. 1999. Induced responses to herbivory in wild radish: Effects on several herbivores and plant fitness. Ecology 80:1713-1723.

Agrawal, A. A. 2000. Overcompensation of plants in response to herbivory and the by-product benefits of mutualism. Trends in Plant Science 5:309-313.

Armbruster, W. S. 1997. Exaptations link evolution of plantherbivore and plant-pollinator interactions: a phylogenetic inquiry. Ecology 78:1661-1672.

Augspurger, C. K. 1981. Reproductive synchrony of a tropical shrub: experimental studies on effects of pollinators and seed predators on Hybanthus prunifolius (Violaceae). Ecology 62:775-788.

Boose, D. L. 1997. Sources of variation in floral nectar production rate in Epilobium canum (Onagraceae): implications for natural selection. Oecologia 110:493-500.

Branch, G. M., J. M. Harris, C. Parkins, R. H. Bustamate, and S. Eekhout. 1992. Algal "gardening" by grazers: a comparison of the ecological effects of territorial fish and limpets. Pages 405-423 in J. H. Price, editor. Plant-animal interactions in the marine benthos. Clarendon Press, Oxford, UK.

Brody, A. K. 1997. Effects of pollinators, herbivores, and seed predators on flowering phenology. Ecology 78:16241631 .

Brody, A. K., and R. J. Mitchell. 1997. Effects of experimental manipulation of inflorescence size on pollination and pre-dispersal seed predation in the hummingbird-pollinated plant Ipomopsis aggregata. Oecologia 110:86-93.

Bronstein, J. L. 2001a. The costs of mutualism. American Zoologist 41:825-839.

Bronstein, J. L. 2001b. The exploitation of mutualisms. Ecology Letters 4:277-287.

Bultman, T. L., A. M. Welch, R. A. Boning, and T. I. Bowdish. 2000. The cost of mutualism in a fly-fungus interaction. Oecologia 124:85-90.

Campbell, D. R., N. M. Waser, M. V. Price, E. A. Lynch, and R. J. Mitchell. 1991. Components of phenotypic selection: pollen export and lower corolla width in Ipomopsis aggregata. Evolution 45:1458-1467.

Castellanos, M. C., P. Wilson, and J. D. Thomson. 2002. Dynamic nectar replenishment in flowers of Penstemon (Scrophulariaceae). American Journal of Botany 89:111118. 
Chittka, L., and J. Thomson. 2001. Cognitive ecology of pollination: animal behavior and floral evolution. Cambridge University Press, Cambridge, UK.

Conner, J. K., R. Davis, and S. Rush. 1995. The effect of wild radish floral morphology on pollination efficiency by four taxa of pollinators. Oecologia 104:234-245.

Cook, J. M., and J.-Y. Rasplus. 2003. Mutualists with attitude: coevolving fig wasps and figs. Trends in Ecology and Evolution 18:241-248.

Cunningham, J. P., S. A. West, and D. J. Wright. 1998. Learning in the nectar foraging behaviour of Helicoverpa armigera. Ecological Entomology 23:363-369.

de Mazancourt, C., M. Loreau, and U. Dieckmann. 2001. Can the evolution of plant defense lead to plant-herbivore mutualism? American Naturalist 158:109-123.

De Moraes, C. M., M. C. Mescher, and J. H. Tumlinson. 2001. Caterpillar-induced nocturnal plant volatiles repel nonspecific females. Nature 410:577-580.

Dufaÿ, M., and M.-C. Anstett. 2003. Conflicts between plants and pollinators that reproduce within inflorescences: evolutionary variations on a theme. Oikos 100:3-14.

Elle, E., and J. D. Hare. 2002. Environmentally-induced variation in floral traits affecting the mating system in Datura wrightii. Functional Ecology 16:79-88.

Elmqvist, T., D. Liu, U. Carlsson, and B. E. Giles. 1993 Anther-smut infection in Silene dioica: variation in floral morphology and patterns of spore deposition. Oikos 68 207-216.

Euler, M., and I. T. Baldwin. 1996. The chemistry of defense and apparency in the corollas of Nicotiana attenuata. Oecologia 107:102-112.

Fineblum, W. L., and M. D. Rausher. 1997. Do floral pigmentation genes also influence resistance to enemies? The W locus in Ipomoea purpurea. Ecology 78:1646-1654.

Flint, H. M., N. J. Curtice, and F. D. Wilson. 1988. Development of pink bollworm populations (Lepidoptera: Gelechiidae) on nectaried and nectariless deltapine cotton in field cages. Environmental Entomology 17:306-308.

Galen, C., and J. Cuba. 2001. Down the tube: pollinators, predators, and the evolution of flower shape in the alpine skypilot, Polemonium viscosum. Evolution 55:1963-1971.

Gardener, M. C., and M. P. Gillman. 2001a. The effects of soil fertilizer on amino acids in the floral nectar of corncockle, Agrostemma githago (Caryophyllaceae). Oikos 92: 101-106.

Gardener, M. C., and M. R. Gillman. 2001b. Analyzing variability in nectar amino acids: composition is less variable than concentration. Journal of Chemical Ecology 27:25452558 .

Gardener, M. C., and M. P. Gillman. 2002. The taste of nectar-a neglected area of pollination ecology. Oikos 98: $552-557$.

Gill, F. B., and C. A. Conway. 1979. Floral biology of Leonotis nepetifolia (L.) R. Br. (Labiatae). Proceedings of the National Academy of Sciences (USA) 131:244-256.

Gomulkiewicz, R., S. L. Nuismer, and J. N. Thompson. 2003. Coevolution in variable mutualisms. American Naturalist 162: S80-S93.

Grosskopf, G., L. A. Smith, and P. Syrett. 2002. Host range of Cheilosia urbana (Meigen) and Cheilosia psilophthalma (Becker) (Diptera: Syrphidae), candidates for the biological control of invasive alien hawkweeds (Hieracium spp., Asteraceae) in New Zealand. Biological Control 24:7-19.

Herrera, C. M. 2000. Measuring the effects of pollinators and herbivores: evidence for non-additivity in a perennial herb. Ecology 81:2170-2176.

Herrera, C. M., M. Medrano, P. J. Rey, A. M. Sanchez-Lafuente, M. B. Garcia, J. Guitian, and A. J. Manzaneda. 2002. Interaction of pollinators and herbivores on plant fitness suggests a pathway for correlated evolution of mutualism- and antagonism-related traits. Proceedings of the National Academy of Sciences (USA) 99:16823-16828.

Hodges, R. W. 1971. The moths of America north of Mexico: Sphingoidea. E. W. Classey and R. B. D. Publications, London, UK.

Hodges, S. A. 1995. The influence of nectar production on hawkmoth behavior, self pollination, and seed production in Mirabilis multiflora (Nyctaginaceae). American Journal of Botany 82:197-204.

Irwin, R. E., A. K. Brody, and N. M. Waser. 2001. The impact of floral larceny on individuals, populations, and communities. Oecologia 129:161-168.

Irwin, R. E., S. Y. Strauss, S. Storz, A. Emerson, and G. Guibert. 2003. The role of herbivores in the maintenance of a flower-color polymorphism in wild radish. Ecology 84: 1733-1743.

Janzen, D. H. 1984. Dispersal of small seeds by big herbivores: foliage is the fruit. American Naturalist 123:338353.

Karban, R. 1997. Neighbourhood affects a plant's risk of herbivory and subsequent success. Ecological Entomology 22:433-439.

Kester, K. M., S. C. Peterson, F. Hanson, D. M. Jackson, and R. F. Severson. 2002. The roles of nicotine and natural enemies in determining larval feeding site distributions of Manduca sexta L. and Manduca quinquemaculata (Haworth) on tobacco. Chemoecology 12:1-10.

Littell, R. C., W. W. Stroup, and R. J. Freund. 2002. SAS for linear models. Fourth edition. SAS Institute, Cary, North Carolina, USA.

Lukefahr, M. J., and C. Rhyne. 1960. Effects of nectariless cottons on populations of three lepidopterous insects. Journal of Economic Entomology 53:242-244.

Madden, A. H., and F. S. Chamberlin. 1945. Biology of the tobacco hornworm in the southern cigar tobacco district. U.S. Department of Agriculture Technical Bulletin 896.

Maloof, J. E., and D. W. Inouye. 2000. Are nectar robbers cheaters or mutualists? Ecology 81:2651-2661.

McFadden, M. W. 1968. Observations on feeding and movement of tobacco hornworm larvae. Journal of Economic Entomology 61:352-356.

Mira, A., and E. A. Bernays. 2002. Trade-offs in host use by Manduca sexta: plant characters vs natural enemies. Oikos 97:387-397.

Mitchell, R. J. 2004. Heritability of nectar traits: why do we know so litte? Ecology 85:1527-1533.

Motten, A. F., and J. Antonovics. 1992. Determinants of outcrossing rate in a predominantly self-fertilizing weed, $D a$ tura stramonium (Solanaceae). American Journal of Botany 79:419-427.

Murphy, D. D., M. S. Menninger, and P. R. Ehrlich. 1984. Nectar source distribution as a determinant of oviposition host species in Euphydryas chalcedona. Oecologia 62:269271.

Nitao, J. K., and A. R. Zangerl. 1987. Floral development and chemical defense allocation in wild parsnip (Pastinaca sativa). Ecology 68:521-529.

Nuñez-Farfan, J., R. A. Cabrales Vargas, and R. Dirzo. 1996. Mating system consequences on resistance to herbivory and life history traits in Datura stramonium. American Journal of Botany 83:1041-1049.

Nuñez-Farfán, J., and R. Dirzo. 1994. Evolutionary ecology of Datura stramonium L in central Mexico: natural selection for resistance to herbivorous insects. Evolution 48: 423-436.

Offenberg, J. 2001. Balancing between mutualism and exploitation: the symbiotic interaction between Lasius ants and aphids. Behavioral Ecology and Sociobiology 49:304310 .

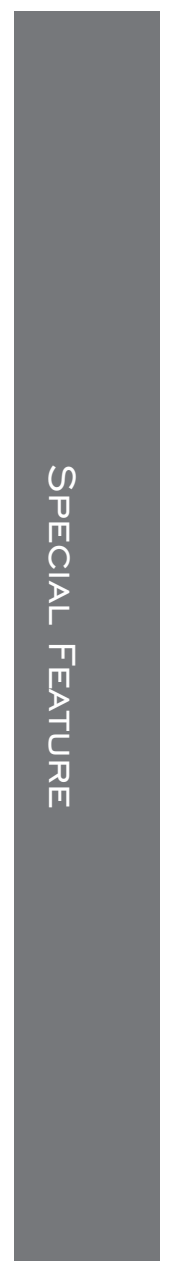


Pellmyr, O. 2003. Yuccas, yucca moths, and coevolution: a review. Annals of the Missouri Botanical Garden 90:3555.

Pettersson, M. W. 1994. Large plant size counteracts early seed predation during the extended flowering season of a Silene uniflora (Caryophyllaceae) population. Ecography 17:264-271.

Proctor, M., P. Yeo, and A. Lack. 1996. The natural history of pollination. Timber Press, Portland, Oregon, USA.

Raguso, R. A., C. Henzel, S. L. Buchmann, and G. P. Nabhan. 2003. Trumpet flowers of the Sonoran Desert: do Peniocereus cacti mimic Datura flowers? International Journal of Plant Science 164:877-892.

Ramsey, M. W. 1988. Differences in pollinator effectiveness of birds and insects visiting Banksia menziesii (Proteaceae). Oecologia 76:119-124.

Real, L. A., and B. J. Rathcke. 1991. Individual variation in nectar production and its effect on fitness in Kalmia latifolia. Ecology 72:149-155.

Rudgers, J. A., and M. C. Gardener. 2004. Extrafloral nectar as a resource mediating multispecies interactions. Ecology 85:1495-1502.

Schuster, M. F., M. J. Lukefahr, and F. G. Maxwell. 1976. Impact of nectariless cotton on plant bugs and natural enemies. Journal of Economic Entomology 69:400-402.

Scott, W. P., G. L. Snodgrass, and J. W. Smith. 1988. Tarnished plant bug (Hemiptera: Miridae) and predaceous arthropod populations in commercially produced selected nectaried and nectariless cultivars of cotton. Journal of Entomological Science 23:280-286.

Shonle, I., and J. Bergelson. 2000. Evolutionary ecology of the tropane alkaloids of Datura stramonium L. (Solanaceae). Evolution 54:778-788.

Shykoff, J. A., and E. Bucheli. 1995. Pollinator visitation patterns, floral rewards and the probability of transmission of Microbotryum violaceum, a venereal disease of plants Journal of Ecology 83:189-198.

Shykoff, J. A., E. Bucheli, and O. Kaltz. 1997. Anther smut disease in Dianthus silvester (Caryophyllaceae): natural selection on floral traits. Evolution 51:383-392.

Simms, E. L., and M. A. Bucher. 1996. Pleiotropic effect of flower color intensity on resistance to herbivory in Ipomoea purpurea. Evolution 50:957-963.

Simpson, B. B., and J. L. Neff. 1983. Evolution and diversity of floral rewards. Pages 142-159 in R. F. Little, editor.
Handbook of experimental pollination biology. Van Nostrand Reinhold, New York, New York, USA.

Stanton, M. L., A. A. Snow, S. N. Handel, and J. Bereczky. 1989. The impact of a flower-color polymorphism on mating patterns in experimental populations of wild radish ( $R a$ phanus raphanistrum L). Evolution 43:335-346.

Strauss, S. Y. 1997. Floral characters link herbivores, pollinators, and plant fitness. Ecology 78:1640-1645.

Strauss, S. Y., R. E. Irwin, and V. Lambrix. 2004. Optimal defense theory and flower petal color predict variation in the secondary chemistry of wild radish. Journal of Ecology 92:132-141.

Strauss, S. Y., D. H. Siemens, M. B. Decher, and T. MitchellOlds. 1999. Ecological costs of plant resistance to herbivores in the currency of pollination. Evolution 53:11051113.

Thompson, J. N., and B. M. Cunningham. 2002. Geographic structure and dynamics of coevolutionary selection. Nature 417:735-738.

Valverde, P. L., J. Fornoni, and J. Nunez-Farfan. 2001. Defensive role of leaf trichomes in resistance to herbivorous insects in Datura stramonium. Journal of Evolutionary Biology 14:424-432.

Vander Wall, S. B. 2001. The evolutionary ecology of nut dispersal. Botanical Review 67:74-117.

Vogel, S. 1978. Evolutionary shifts from reward to deception in pollen flowers. Pages 89-96 in C. P. Read, editor. Parasitism and symbiology. Ronald, New York, New York, USA.

Willmott, A. P., and A. Burquez. 1996. The pollination of Merremia palmeri (Convolvulaceae): can hawk moths be trusted? American Journal of Botany 83:1050-1056.

Wilson, P., and J. D. Thomson. 1991. Heterogeneity among floral visitors leads to discordance between removal and deposition of pollen. Ecology 72:1503-1507.

Wolfe, L. M. 1997. Differential flower herbivory and gall formation on males and females of Neea psychotrioides, a dioecious tree. Biotropica 29:169-174.

Wyatt, R., S. B. Broyles, and G. S. Derda. 1992. Environmental influences on nectar production in milkweeds (Asclepias syriaca and A. exaltata). American Journal of Botany 79:636-642.

Zangerl, A. R., and C. E. Rutledge. 1996. The probability of attack and patterns of constitutive and induced defense: a test of optimal defense theory. American Naturalist 147: 599-608. 